\title{
Natural manganese deposits as catalyst for decomposing hydrogen peroxide
}

\author{
A. H. Knol ${ }^{1}$, K. Lekkerkerker-Teunissen ${ }^{1}$, and J. C. van Dijk ${ }^{2}$ \\ ${ }^{1}$ Dunea N.V., Strategy department, P.O. Box 756, 2700 AT Zoetermeer, the Netherlands \\ ${ }^{2}$ Delft University of Technology, Stevinweg 1, 2628 CN Delft, the Netherlands
}

Correspondence to: A. H. Knol (t.knol@dunea.nl)

Received: 17 November 2014 - Published in Drink. Water Eng. Sci. Discuss.: 23 January 2015

Revised: 7 April 2015 - Accepted: 8 April 2015 - Published: 22 April 2015

\begin{abstract}
Drinking water companies (are intending to) implement advanced oxidation processes (AOP) in their treatment schemes to increase the barrier against organic micropollutants (OMPs). It is necessary to decompose the excessive hydrogen peroxide after applying AOP to avoid negative effects in the following, often biological, treatment steps. A drinking water company in the western part of the Netherlands investigated decomposition of about $5.75 \mathrm{mg} \mathrm{L}^{-1}$ hydrogen peroxide in pre-treated Meuse river water with different catalysts on pilot scale.

In down flow operation, the necessary reactor empty bed contact time (EBCT) with the commonly used granulated activated carbon (GAC) and waste ground water filter gravel (MCFgw) were found equal with $149 \mathrm{~s}$, corresponding with a conversion rate constant $r$ of $0.021 \mathrm{~s}^{-1}$. The EBCT of the fine coating of ground water filter gravel (MC) was significantly shorter with a little more than $10 \mathrm{~s}\left(r=0.30 \mathrm{~s}^{-1}\right)$.

In up flow operation, with a flow rate of $20 \mathrm{~m} \mathrm{~h}^{-1}$, the EBCT of coating MC increased till about $100 \mathrm{~s}$ $\left(r=0.031 \mathrm{~s}^{-1}\right)$, from which can be concluded, that the performance of this waste material is better compared with GAC, in both up and down flow operation.

The necessary EBCT at average filtration rate of full scale dual layer filter material (MCFsw) amounted to $209 \mathrm{~s}\left(r=0.015 \mathrm{~s}^{-1}\right)$. Regarding the average residence time in the full scale filters of $700 \mathrm{~s}$, applying AOP in front of the filters could be an interesting alternative which makes a separate decomposition installation superfluous, on the condition that the primary functions of the filters are not affected.
\end{abstract}

\section{Introduction}

All over the world surface water is to some extend contaminated with organic micropollutants (OMPs) (Houtman et al., 2010). It is expected that the amount and concentrations of OMPs will increase, due to population growth, aging and global warming (Wuijts et al., 2013). A drinking water company in the western part of the Netherlands identified the threat of OMPs in their source the Afgedamde Maas, a side branch of the Meuse river. The managed aquifer recharge (MAR) by dune filtration and the dosing of powdered activated carbon (PAC) are currently the main barriers against OMPs. After careful consideration advanced oxidation process (AOP) was selected as the most optimal technique to extend the treatment scheme (Abrahamse et al., 2007) and research was carried out with ozone and UV based AOP, in combination with hydrogen peroxide. When AOP is installed before MAR it is expected that this two processes will provide a synergistic, hybrid system (Lekkerkerker-Teunissen et al., 2012).

A drawback of applying AOP is the remaining hydrogen peroxide in the treated water. After dosing $6 \mathrm{mg} \mathrm{L}^{-1}$ hydrogen peroxide in the AOP influent water, about $5.75 \mathrm{mg} \mathrm{L}^{-1}$ hydrogen peroxide is remaining in the AOP effluent water. This AOP effluent water flows out in infiltration ponds which recharge the dunes. It is established that even a concentration of $2 \mathrm{mg} \mathrm{L}^{-1}$ affects about $80 \%$ of the organisms in the infiltration ponds (Reeze et al., 2010). Because the infiltration ponds are situated in a protected nature area (Natura 2000), it is of utmost importance to lower the hydrogen peroxide concentration till a level that will not affect the ecology. As 
a company standard, the maximum allowed concentration of hydrogen peroxide in the infiltrated water is established at $0.25 \mathrm{mg} \mathrm{L}^{-1}$.

Hydrogen peroxide in water has a tendency to decompose in water and oxygen, because the reaction products are more stable than the hydrogen peroxide itself (Petrucci, 2007):

$2 \mathrm{H}_{2} \mathrm{O}_{2} \rightarrow 2 \mathrm{H}_{2} \mathrm{O}+\mathrm{O}_{2}$

$\Delta \mathrm{H}\left[\mathrm{kJ} \mathrm{mol}^{-1}\right] 2 \times-134.1 \rightarrow 2 \times-237.2+0.0$

Overall the chemical drive of this so-called decomposition reaction is $206.2 \mathrm{kJmol}^{-1}$. However, the decomposition is very slow, the reason why hydrogen peroxide solutions are commercially available. Decomposition is strongly affected by light and catalysts as catalase, (spores of) metal oxides and activated carbon. In full-scale application, homogeneous catalysis (enzymatic with for example catalase or iron) is not practical. The most promising technique is therefore heterogeneous catalysis. Common catalysts include manganese oxide, silver, platinum and activated carbon. The surface of these catalysts provides a favorable environment to catalyze the decomposition, though the mechanism is not well understood. According to Masel et al. (2001) the reaction rate is increased as this alternative route has a lower activation energy than without the catalyst. Decomposition starts with adsorption of hydrogen peroxide on the catalyst. The rate of adsorption, and with that the decomposition rate, is higher at higher water temperature and with a larger catalyst surface.

Filtration over granulated activated carbon (GAC) is a proven technology to decompose hydrogen peroxide (Kruithof et al., 2007). The decomposition reaction with pure manganese dioxide in granular form is slow and time demanding (Bazri, 2008). However, Miller et al. (1999) reported decomposition of hydrogen peroxide in the presence of sandy material from an aquifer and riverbed. The sand was naturally coated with metal oxides, from which manganese oxide was most active. It was known that dissolved manganese in surface and groundwater deposits as natural manganese oxide compounds on grains in sand filters of drinking water treatment plants. Merkle et al. (1996) measured a high specific surface area of naturally coated filter material, which increases with the amount of manganese coating. Decomposing hydrogen peroxide with existing or waste filter material will contribute to a sustainable society. As a proof of principle, $1 \%$ hydrogen peroxide solution was added to grains of a full-scale double layer sand filter of a drinking water treatment plant. Microscopic examination yielded promising results: (oxygen) bubbles were formed at the surface of the grains.

This research focused on the decomposition of about 5 and $10 \mathrm{mg} \mathrm{L}^{-1}$ hydrogen peroxide till $0.25 \mathrm{mg} \mathrm{L}^{-1}$ in the pilot plant installation. Three different catalysts were investigated: commonly applied GAC and two types of manganese coated filter material. The main parameter determined for the three decomposing materials was the reactor empty bed contact time (EBCT), based on the conversion rate of the decomposition.

\section{Materials and methods}

\subsection{Column reactors}

Catalytic decomposition was investigated in vertical column reactors, with outside diameters of $0.20,0.40$ and $0.60 \mathrm{~m}$, called R20, R40 and R60, respectively. Sample points over the height of the columns made it possible to analyse the hydrogen peroxide after different contact times. The two reactors R60 were fed with pre-treated Meuse river water, abstracted before the full-scale double layer sand filters. The reactors R20 and R40 were fed with the effluent of these fullscale double layer sand filters. The flow through the reactors could be varied between 1.0 and $3.0 \mathrm{~m}^{3} \mathrm{~h}^{-1}$, which corresponds with flow rates between 4 and $100 \mathrm{~m} \mathrm{~h}^{-1}$. The standard operation was down flow, but up flow operation also was applied with flow rates up till $40 \mathrm{~m} \mathrm{~h}^{-1}$. Before the water flowed in the reactors, $10 \%$ hydrogen peroxide was dosed into the water with a membrane pump with a maximum capacity of $3.0 \mathrm{~L} \mathrm{~h}^{-1}$. The applied concentrations were about 5 and $10 \mathrm{mg} \mathrm{L}^{-1}$ in the influent water.

\subsection{Decomposing material}

Three different catalysts were investigated: fresh GAC and two types of used manganese coated filter material. The filter materials were collected from full-scale filters at drinking water treatment plants.

The GAC type was extruded activated carbon with a diameter of $0.8 \mathrm{~mm}$, especially suitable for catalytic processes. The manganese coated filter material were obtained from two different drinking water treatment facilities.

The first manganese coated filter material was obtained from a ground water treatment plant (MCFgw). This filter material is regularly replaced by fresh sand as a result of the rapid growth of the grain size by the coating, resulting in a lower purification performance. A sample is taken at the end of the filter life time of 7 years. Especially ground water may contain a high content of manganese, which may be makes the replaced grains suitable for decomposing hydrogen peroxide. The second manganese coated filter material was obtained from a surface water treatment plant (MCFsw). The MCFsw was collected from a double layer sand filter, with a filter life time of 31 years. In order to clean the grains after filling the reactor, MCFgw was backwashed with water before the first tests. During backwashing, a part of the coating was separated from the grains and formed a top layer. This top layer of fine coating was removed from the reactor and also used as catalyst (MC). 
Table 1. Specifications of different tested filter gravels.

\begin{tabular}{llrrr}
\hline Parameter & Unit & $\begin{array}{r}\text { Course gravel } \\
\text { MCFgw }\end{array}$ & $\begin{array}{r}\text { Coating } \\
\text { MC }\end{array}$ & $\begin{array}{r}\text { Anthracite/sand } \\
\text { MCFsw }\end{array}$ \\
\hline $10 \%$ Grain & $\mathrm{mm}$ & 1.01 & 0.25 & $2.06 / 0.97$ \\
Uniformity 60/10\% & - & 2.26 & 2.02 & $1.18 / 1.13$ \\
Manganese content & $\mathrm{g} \mathrm{kg}^{-1}$ & 14.0 & 100.0 & $0.15 / 0.09$ \\
Specific surface area* & $\mathrm{m}^{2} \mathrm{~g}^{-1}$ & 4.0 & 64 & $1.9 / 2.1$ \\
\hline
\end{tabular}

* BET surface area by $\mathrm{N}_{2}$ adsorption.

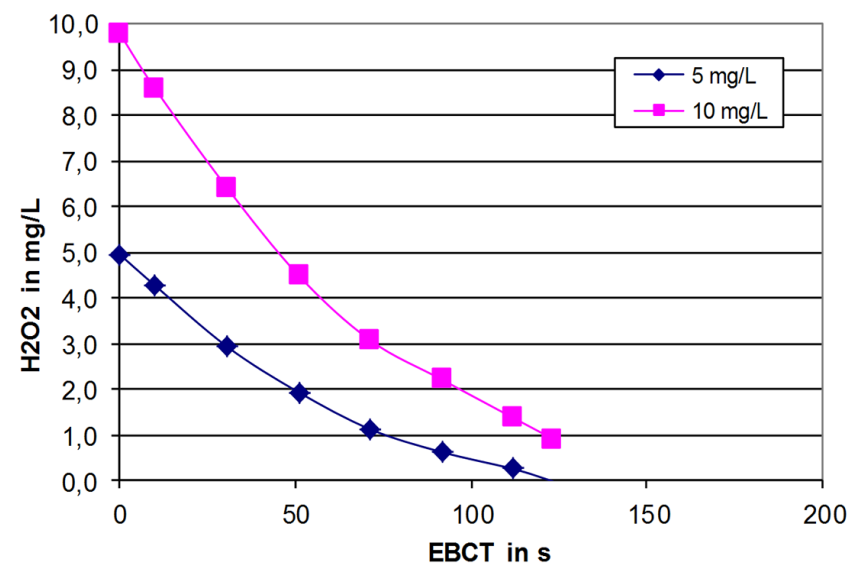

Figure 1. Decomposition of hydrogen peroxide with ROW 0.8 cat in R20 (bed height $1.4 \mathrm{~m}$, flow rate $40 \mathrm{~m} \mathrm{~h}^{-1}$, water temperature $\left.1.8^{\circ}\right)$.

\subsection{Analyses}

The hydrogen peroxide concentration in water was analysed on site with a spectrophotometer. The measurement is based on the reaction of hydrogen peroxide with titanium(IV)oxysulphate solution, following DIN 38409 H15. Samples were collected and measured in a volumetric flask, after adding $5.0 \mathrm{~mL}$ of the titanium(IV)oxysulphate solution by a pipette. When higher concentrations were expected than $6 \mathrm{mg} \mathrm{L}^{-1}$, the samples were diluted with milli-q water. The samples were measured at a wavelength of $420 \mathrm{~nm}$ and corrected for background absorbance, which were determined by analysing the samples without the addition of titanium(IV)oxysulphate solution. At a hydrogen peroxide concentration of $5.8 \mathrm{mg} \mathrm{L}^{-1}$ the standard deviation $\sigma$ was $0.02 \mathrm{mg} \mathrm{L}^{-1}$.

\section{Results and discussion}

\subsection{Activated carbon}

With GAC in down flow operation, $5 \mathrm{mg} \mathrm{L}^{-1}$ hydrogen peroxide was decomposed completely in just more than $120 \mathrm{~s}$ empty bed contact time (EBCT), see Fig. 1. In the same EBCT, $10 \mathrm{mg} \mathrm{L}^{-1}$ hydrogen peroxide was decomposed for

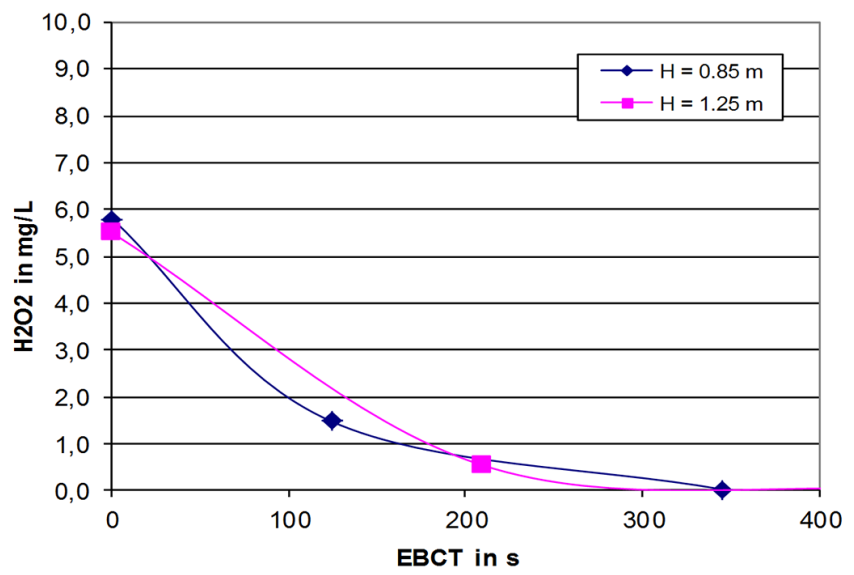

Figure 2. Decomposition over MCFsw in R60s with a bed height of $0.85 \mathrm{~m}(0.6 \mathrm{~m}$ gravel $0.8-1.2 \mathrm{~mm}$ and $0.25 \mathrm{~m}$ anthracite $1.4-$ $2.4 \mathrm{~mm})$ and a bed height of $1.25 \mathrm{~m}(1.0 \mathrm{~m}$ gravel $0.8-1.2 \mathrm{~mm}$ and $0.25 \mathrm{~m}$ anthracite $1.4-2.4 \mathrm{~mm}$ ), a flow velocity of $4.4 \mathrm{~m} \mathrm{~h}^{-1}$, and a water temperature of $12.4^{\circ} \mathrm{C}$.

about $90 \%$. This experiment confirmed that activated carbon is well-functioning catalyst for decomposing hydrogen peroxide, even at the low water temperature of $1.8^{\circ} \mathrm{C}$.

\subsection{Manganese coated filter material}

\subsubsection{Specifications}

The manganese content of MCFgw is about 100 times higher than from MCFsw due to the higher manganese concentration in groundwater (Table 1). The specific surface area is twice as high. MC is characterized by a high manganese content and specific surface area and small grain size.

With XRD analysis, besides calcium and iron compounds, the manganese containing compounds ramsdellite and birnessite were detected in MC (Hendrix, 2014).

\subsubsection{Decomposition rate}

The decomposition rate of the different manganese containing materials are investigated in down flow operation. The decomposition of $5 \mathrm{mg} \mathrm{L}^{-1}$ hydrogen peroxide with anthracite and gravel MCFsw is plotted in Fig. 2. 


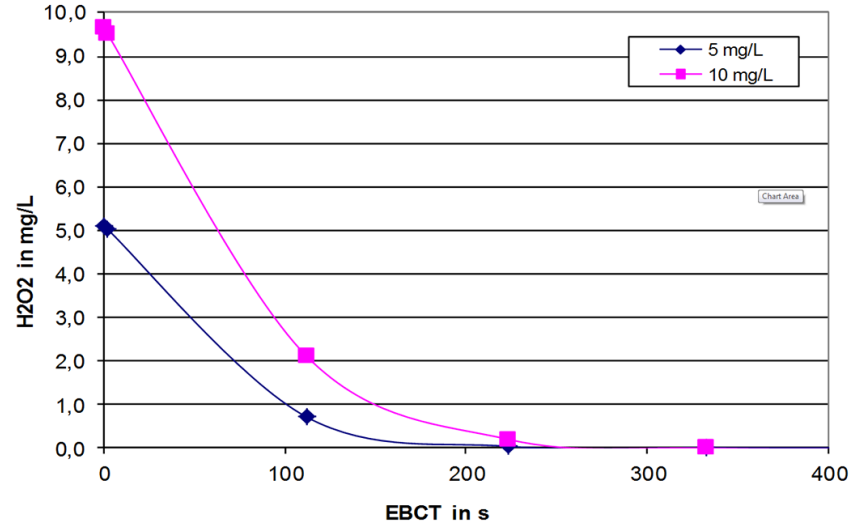

Figure 3. Decomposition over MCFgw in R40 (bed height $2.3 \mathrm{~m}$, flow rate $25 \mathrm{~m} \mathrm{~h}^{-1}$, water temperature $3.3^{\circ} \mathrm{C}$ ).

In about 250 till $350 \mathrm{~s}$ the hydrogen peroxide in both reactors was decomposed completely. The EBCT of the $0.25 \mathrm{~m}$ anthracite layer was about $200 \mathrm{~s}$, which means that the anthracite had a major contribution to the decomposition. The total EBCT of $700 \mathrm{~s}$ of the $0.85 \mathrm{~m}$ bed layer was the same as the average EBCT in the full scale filters, which means that at least $400 \mathrm{~s}$ EBCT remains for the primary functions of the rapid sand filters (removal of iron and manganese, nitrification and mineralization). This observation confirms that applying AOP in front of the rapid sand filters can be an interesting option in practice and could make a separate decomposing installation superfluous, provided that the primary filter functions are not disturbed.

Decomposing with the coarse gravel MCFgw was investigated with a dose of 5 and $10 \mathrm{mg} \mathrm{L}^{-1}$ (Fig. 3).

A dose of $5 \mathrm{mg} \mathrm{L}^{-1}$ hydrogen peroxide was completely decomposed in an EBCT of $180 \mathrm{~s}$. A dose of $10 \mathrm{mg} \mathrm{L}^{-1}$ was decomposed in $260 \mathrm{~s}$. Despite the manganese content of MCFgw of $14 \mathrm{~g} \mathrm{~kg}^{-1}$, about 100 times higher compared to MCFsw, and twice as large specific surface area, $4.0 \mathrm{~m}^{2} \mathrm{~g}^{-1}$ compared to $1.9 / 2.1 \mathrm{~m}^{2} \mathrm{~g}^{-1}$, the difference in the decomposing time between MCFgw and MCFsw was no more than $30 \%$. Possibly a part of the manganese oxides in MCFgw were enclosed and did not contribute to the decomposition.

The results of decomposition with the fine coating MC was investigated with a dose of $5 \mathrm{mg} \mathrm{L}^{-1}$ hydrogen peroxide and plotted in Fig. 4.

Already within $10 \mathrm{~s} 95 \%$ of the hydrogen peroxide was decomposed. Clearly the coating with a relatively high manganese content of $100 \mathrm{~g} \mathrm{~kg}^{-1}$ had a positive effect on the rate constant of decomposing hydrogen peroxide, conform literature (Bazri, 2008). In addition, the small particles and high specific surface area (Table 1) form a large catalyst surface.

Decomposition of hydrogen peroxide is a first order reaction in a heterogeneous environment. Because the reaction does not take place under homogenous circumstances, the decomposition rate is not expressed in a reaction rate con-

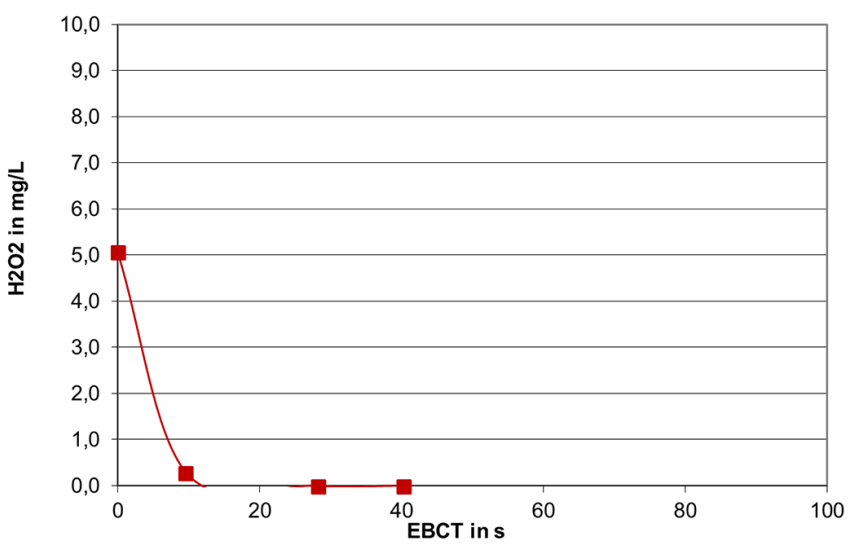

Figure 4. Decomposition over MC in R20 (bed height $0.36 \mathrm{~m}$, flow rate $40 \mathrm{~m} \mathrm{~h}^{-1}$, water temperature $11.7^{\circ} \mathrm{C}$ ).

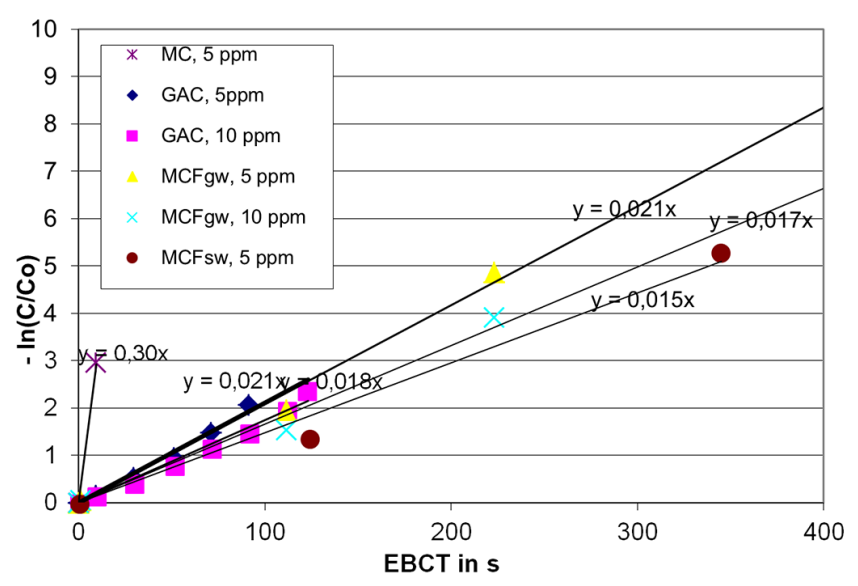

Figure 5. Conversion rate constants of the different tested catalysts.

stant, but in the conversion rate constant $r$ (Coulson et al., 1996). The conversion rate constant is not only depending of temperature and pressure (as in homogeneous milieu), but also on contact surface of the catalyst and hydraulic conditions in the reactor. In case of a first order reaction, a linear relation exist between the negative natural logarithm of the quotient of the effluent hydrogen peroxide $C$ and influent concentration $C_{0}$ and the reaction time $\left(-\ln C / C_{0}\right.$ vs. $\left.t\right)$. The relations of the different investigated catalysts are plotted in Fig. 5.

MC had the highest conversion rate constant (note that the value of $r$ is only based on one sample point, because the water in the second sample point did not contain hydrogen peroxide anymore) and much higher compared to the other catalysts. The high specific surface area of $64 \mathrm{~m}^{2} \mathrm{~g}^{-1}$, the high manganese content in the form of (partly) ramsdellite and small grain size, all three factors contributed to the high conversion rate. Páez et al. (2011) also reported high conversion rate constants with synthesized small nano-needle particals ramsdellite $(\varnothing=10 \mathrm{~nm}, L=180 \mathrm{~nm})$. In batch opera- 


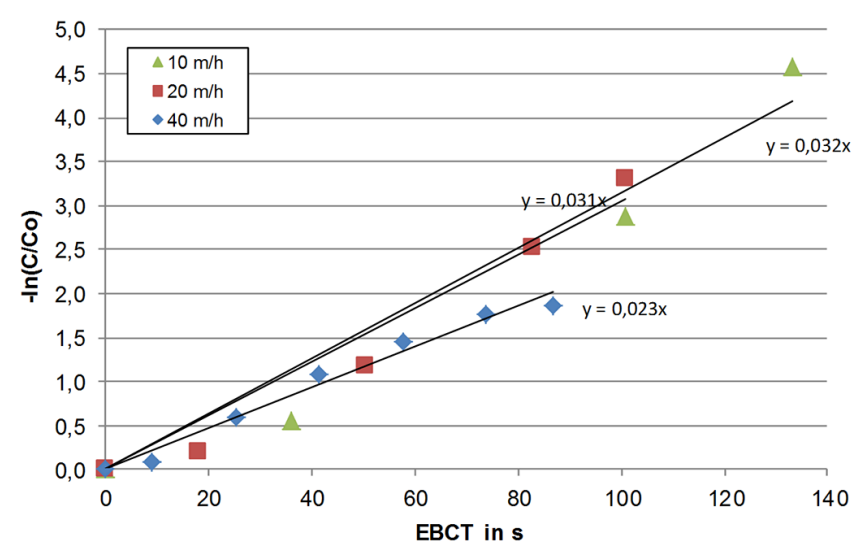

Figure 6. Up flow decomposition with MC in R20 (static bed height $0.36 \mathrm{~m}$, water temperature $5.8^{\circ} \mathrm{C}$ ).

Table 2. EBCT of catalysts to decompose a peroxide concentration of $C_{0}=5.75 \mathrm{mg} \mathrm{L}^{-1}$ till $C=0.25 \mathrm{mg} \mathrm{L}^{-1}$.

\begin{tabular}{lrr}
\hline Catalyst & $r\left(\mathrm{~s}^{-1}\right)$ & EBCT $(\mathrm{s})$ \\
\hline MCFsw & 0.015 & 209 \\
GAC & 0.021 & 149 \\
MCFgw & 0.021 & 149 \\
MC & 0.30 & 10.4 \\
\hline
\end{tabular}

tion a conversion rate constant was measured of $0.015 \mathrm{~s}^{-1}$ after addition of only $0.374 \mathrm{~g} \mathrm{~L}^{-1}$ particles.

The conversion rate constant of $0.015 \mathrm{~s}^{-1}$ of MCFsw is in line with the reported conversion rate constant of $0.007 \mathrm{~s}^{-1}$ during column experiments with sandy aquifer material with different metal deposits, from which manganese appeared to have the biggest contribution to the decomposition (Miller et al., 1995). Not only the manganese content of $0.06 \mathrm{~g} \mathrm{~kg}^{-1}$ of the sandy aquifer material was comparable with MCFsw $\left(0.15 / 0.09 \mathrm{~g} \mathrm{~kg}^{-1}\right)$, but also the specific surface area of $1.75 \mathrm{~g} \mathrm{~m}^{-2}$ (MCFsw 1.9/2.1 $\mathrm{g} \mathrm{m}^{-2}$ ).

In addition, the conversion rate of the same catalyst depended on the initial hydrogen peroxide concentration. This observation is reported earlier under heterogeneous conditions by Coulson et al. (1996).

In Table 2 the necessary EBCT is calculated for the investigated catalysts with an initial concentration $C_{0}=$ $5.75 \mathrm{mg} \mathrm{L}^{-1}$ (corresponding to a dose in the AOP influent of $6 \mathrm{mg} \mathrm{L}^{-1}$ ) and an effluent concentration $C=0.25 \mathrm{mg} \mathrm{L}^{-1}$ (the allowed concentration in the infiltration ponds), which means that $\ln C_{0} / C=3.135$ and $t=3.135 / r$. Here, it was assumed that the calculated conversion rate constants at about $5.0 \mathrm{mg} \mathrm{L}^{-1}$ hydrogen peroxide will not differ much from the conversion rate constants at $5.75 \mathrm{mg} \mathrm{L}^{-1}$.

The necessary EBCT in the full scale dual layer filters (MCFsw) amounts about $200 \mathrm{~s}$. The EBCTs of GAC and

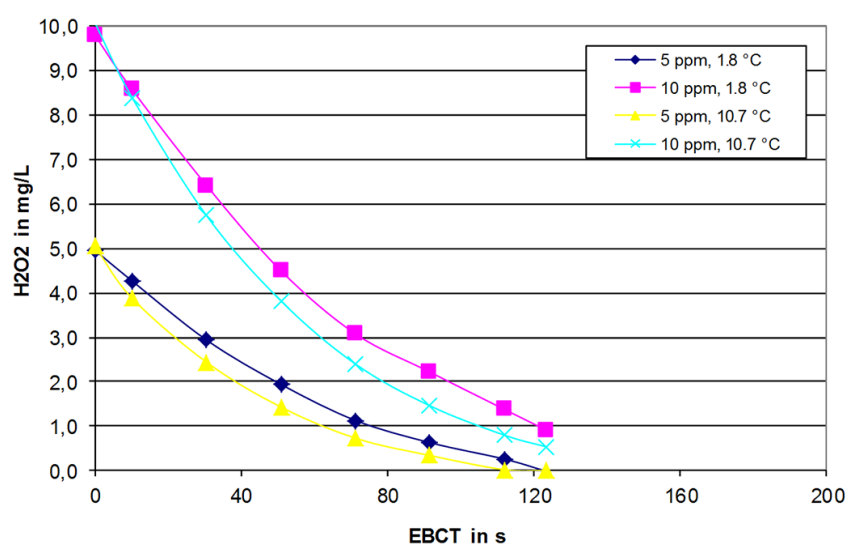

Figure 7. Decomposition with GAC at different water temperatures.

MCFgw equals about $150 \mathrm{~s}$. The EBCT of MC is much lower with approximately $10 \mathrm{~s}$.

\subsubsection{Mode of operation}

For full scale operation down flow operation over fine material has the disadvantage of fast clogging of filter material with suspended particles and potential increase of the resistance due to oxygen bubble formation, depending of the oxygen saturation degree of the water. These disadvantages could be solved by up flow operation.

Up flow operation of the coating MC was investigated using three different flow rates. A flow velocity of $40 \mathrm{~m} \mathrm{~h}^{-1}$ appeared to be the maximum velocity, without carrying the coatings with the effluent of the reactor. The coatings became in fluidised state at a flow velocity of $4 \mathrm{~m} \mathrm{~h}^{-1}$. The decomposition of $5.8 \mathrm{mg} \mathrm{L}^{-1}$ hydrogen peroxide is plotted in Fig. 6 .

From Fig. 6 it was concluded, that the decomposition was sufficient, which means $\ln C_{0} / C \geq 3.135$, with up flow velocities of 10 and $20 \mathrm{~m} \mathrm{~h}^{-1}$. The necessary EBCT was approximately $100 \mathrm{~s}$. At a velocity of $40 \mathrm{~m} \mathrm{~h}^{-1}$ the decomposition goal could not be achieved. Presumably, the adsorption of hydrogen peroxide on the catalyst was inadequate due to the increased expansion of up to $170 \%$, which resulted in less catalyst surface in the same reactor height.

Pelleting MC till a diameter of about $2 \mathrm{~mm}$ would make higher flow velocities possible, and with that a smaller reactor footprint. However, changing the diameter or the surface area of the catalyst or the hydraulic conditions in the reactor, will have impact on the value of the conversion rate constant and consequentially on the design criteria. In addition, the decomposition of hydrogen peroxide depends on the water temperature and will be faster with increasing water temperature. This is visible in Fig. 7, wherein the decomposition is plotted of experiments with GAC at 1.8 and $10.7^{\circ} \mathrm{C}$. The concentration of hydrogen peroxide was always lower after the same contact time at a higher water temperature. 


\section{Conclusions}

In down flow operation, the necessary EBCT to decompose $5.75 \mathrm{mg} \mathrm{L}^{-1}$ hydrogen peroxide in pre-treated Meuse river water with the commonly used GAC and waste groundwater filter gravel (MCFgw) were the same with about $150 \mathrm{~s}$, corresponding to a conversion rate constant $r$ of $0.021 \mathrm{~s}^{-1}$. The EBCT of the coating of groundwater filter gravel (MC) was much shorter with a little more than $10 \mathrm{~s}\left(r=0.30 \mathrm{~s}^{-1}\right)$.

$\mathrm{MC}$ was suitable for up flow operation till a flow velocity of about $20 \mathrm{~m} \mathrm{~h}^{-1}$. The necessary EBCT was about $100 \mathrm{~s}$ $\left(r=0.031 \mathrm{~s}^{-1}\right)$. At an up flow rate of $40 \mathrm{~m} \mathrm{~h}^{-1}$ the decomposition goal could not be achieved, probably due to the increased porosity in the fluidized bed. Pelleting MC till a diameter of about $2 \mathrm{~mm}$ would make higher up flow velocities possible.

The necessary EBCT at average filtration velocity of dual layer filter material (MCFsw) amounted to about $200 \mathrm{~s}$ $\left(r=0.015 \mathrm{~s}^{-1}\right)$. Regarding the average residence time in the full scale filters of $700 \mathrm{~s}$, applying AOP in front of the filters could be an interesting alternative making a separate decomposition installation superfluous, on the condition that the primary functions of the filters are not affected.

Acknowledgements. The authors would like to thank the staff of treatment location Bergambacht for their technical support.

Edited by: J. Cho

\section{References}

Abrahamse, A. J., IJpelaar, G. F., and Knol, A. H.: Project Uitbreiding Zuivering DZH, optionele technieken en locatie keuze, KWR, Dunea, 2007.

Bazri, M. M.: Assimilable Organic Carbon Formation during Ultraviolet-Hydrogen Peroxide Advanced Oxidation Treatment of Surface Water, University of British Columbia, Vancouver, 2010.
Coulson, J. M. and Richardson, J. F.: Chemical Engineering Part 1, Oxford, Butterworth-Heinemann Ltd, 1996.

Hendrix, R. W. A: XRD analysis of sand grains, Materials Science and Engineering TUDelft, January 2014.

Houtman, C. J.: Emerging contaminants in surface waters and their relevance for the production of drinking water in Europe, J. Integrat. Environ. Sci., 7, 271-295, 2010.

Kruithof, J. C., Kamp, P. C., Bram, J., and Martijn, B. J.: UV/ $\mathrm{H}_{2} \mathrm{O}_{2}$ Treatment: A Practical Solution for Organic Contaminant Control and Primary Disinfection, Ozone, Sci. Engin., 29, 273-280, 2007.

Lekkerkerker-Teunissen, K., Knol, A. H., Altena L. P., Houtman, C. J., Verberk, J. Q. J. C., and van Dijk, J. C.: Serial ozone/peroxide/low pressure UV treatment for synergistic and effective organic micropollutant conversion, Separat. Purificat. Technol., 100, 22-29, doi:10.1016/j.seppur.2012.08.030, 2012.

Masel, R. I.: Chemical Kinetics and Catalysis, Wiley-Interscience, New York, 2001.

Merkle, P. B., Knocke, W., Gallagher, D., Junta-Rosso, J., and Solberg, T.: Characterizing filter media mineral coatings, J. AWWA, 62-72, December 1996.

Miller, C. M. and Valentine, R. L.: Hydrogen peroxide decomposition and quinoline degradation in the presence of aquifer material, Water Res., 29, 2353-2359, 1995.

Miller, C. M. and Valentine, R. L.: Mechanistic studies of surface catalyzed $\mathrm{H}_{2} \mathrm{O}_{2}$, Decomposition and contaminant degradation degradation in the presence of sand, Water Res., 33, 2805-2816, 1999.

Páez, C. A., Liquet D. Y., Calberg, C., Lambert, S. D., Willems, I., Germeau, A., Pirard, J. P., and Heinrichs, B.: Study of photocatalytic decomposition of hydrogen peroxide over ramsdellite$\mathrm{MnO}_{2}$ by $\mathrm{O}_{2}$-pressure monitoring, Catal. Commun., 15, 132 136, 2011.

Petrucci, R. H., Harwood, W. S., Herring, G. E., and Madura, J.: General Chemistry: Principles and Modern Applications, 9th Edn., Harlow, Prentice Hall, 2007.

Reeze, A. J. G., Matthijs, J. C. P., and Pancras, T.: Waterstof peroxide $\left(\mathrm{H}_{2} \mathrm{O}_{2}\right)$ in infiltratieplassen, Eco(toxico)logische effecten en afbraaksnelheid, Arcadis, 14 December 2010.

Wuijts, S., van der Grinten, E., Meijers, E., Bak-Eijsberg, C. I., and Zwolsman, J. J. G.: Impact of climate change on surface water as a resource for drinking water: From problem areas to measures, Dutch Ministry of Infrastructure and Environment, 2013. 